\title{
Levantamento quali-quantitativo da produção científica sobre Ecoturismo no Brasil
}

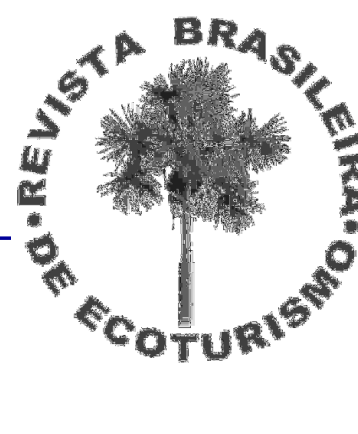

\section{Zysman Neiman, Renata Fronza Saraceni, Stefanie Geerdink}

\begin{abstract}
RESUMO
Num levantamento preliminar de caráter quanti-qualitativo realizado em 2008 verificou-se que doze dos dezesseis grupos de pesquisa em Ecoturismo consolidados encontrados foram formados a partir do ano 2000. Alguns projetos não eram especificamente sobre Ecoturismo, mas tangenciavam o tema, outros foram desativados, e muitos não possuem órgãos fomentadores. Para ampliar este levantamento, entre setembro e novembro de 2009 foi enviado por e-mail um questionário fechado aos participantes com trabalhos inscritos no Congresso Nacional de Ecoturismo (CONECOTUR), realizado no Estado o Espírito Santo, Brasil. Dos 192 trabalhos inscritos, houve o retorno de 135 (70,3\%). Os resultados demonstram que há ainda no país uma pequena quantidade de Grupos de Pesquisa especializados na temática do Ecoturismo, uma vez que a grande maioria dos trabalhos realizados corresponde àqueles realizados por estudantes de graduação e pós-graduação de diversas regiões. A publicação dessa produção ainda se dá através de congressos, uma vez que ainda há poucos periódicos especializados como, por exemplo, a Revista Brasileira de Ecoturismo, que publicou os resumos de todas as pesquisas apresentadas no Congresso Nacional de Ecoturismo. Este trabalho apresenta os resultados quantitativos e qualitativos dessas pesquisas, revelando o substancial crescimento da temática nos cursos universitários de turismo, geografia, biologia e meio ambiente. Uma análise regionalizada também é apresentada, apontando as desigualdades de produção pelas diversas Instituições do país, com destaque para a região sudeste.
\end{abstract}

PALAVRAS-CHAVE: Ecoturismo; Produção Científica; Grupos de Pesquisa Brasileiros.

\section{Quali-quantitative survey of scientific production on Ecotourism in Brazil.}

\section{ABSTRACT}

In a preliminary survey of quantitative and qualitative character conducted in 2008 it was found that twelve of the sixteen consolidated research groups in Ecotourism were formed from the year 2000 on. Some projects were not specifically about Ecotourism, but approached the theme; and others were deactivated, and many of them do not have funding institutions. To extend that survey, between September and November 2009 a closed questionnaire was emailed to participants with entries in the National Ecotourism Congress (CONECOTUR), which was carried out in Espírito Santo, Brazil. 135 (70.3\%) out of 192 submissions were returned. The results show that there is, in the country, a small amount of research groups specialized in the topic of Ecotourism, since the vast majority of the studies corresponds to those made by undergraduate and graduate students in various regions. The publication of such production still takes place in congresses, since there are few specialized journals such as the Brazilian Ecotourism Journal, which published the abstracts of all papers presented at the National Congress of Ecotourism. This paper presents the quantitative and qualitative results of these studies, revealing the substantial growth of this subject in university courses such as: tourism, geography, biology and environment. A regionalized analysis is also presented, pointing out the inequities of production among the various institutions of the country, mostly in the Southeast. 


\section{Introdução}

Uma das modalidades do Turismo na Natureza, o chamado Ecoturismo ou Turismo Ecológico vem crescendo consideravelmente nos últimos anos e sua ampliação deve-se basicamente pelo aumento da preocupação em relação ao meio ambiente e questões referentes à sustentabilidade e cultura, bem como em relação à necessidade humana de mudanças e de experimentação. Além de tratar-se de um movimento turístico recente, se comparado ao turismo de massa, e que possui relevante atuação econômica, social e ambiental (SERRANO, 2000). Considerando os fatores supracitados, o Ecoturismo também possui características como o seu potencial educativo, através da percepção, e de conservação da natureza.

Existem diversas definições e conceituações pertinentes à este segmento, e observa-se que em sua maioria, existem três elementos que compõem o chamado 'tripé' do Ecoturismo: a garantia da Conservação Ambiental, a Educação Ambiental e Benefícios às Comunidades Receptoras. De acordo com as "Diretrizes para uma Política Nacional de Ecoturismo", Ecoturismo é conceituado como:

...um segmento da atividade turística que utiliza, de forma sustentável, o patrimônio natural e cultural, incentiva sua conservação e busca a formação de uma consciência ambientalista através da interpretação do ambiente, promovendo o bem-estar das populações envolvidas (BRASIL, 1994: p.19).

Já Wearing e Neil (2001), consideram que

(...) o ecoturismo pode ser geralmente descrito como um turismo interpretativo, de mínimo impacto, discreto, em que se busca a conservação, o entendimento e a apreciação do meio ambiente e das culturas visitadas. Trata-se de uma área especializada do turismo que inclui viagens para áreas naturais, ou áreas onde a presença humana é mínima, em que o ecoturista envolvido na experiência externa a uma motivação explicita de satisfazer sua necessidade por educação e consciência ambiental, social e/ou cultural por meio da visita à área e a vivencia nela (WEARING; NEIL, 2001: p.5).

Em ambos os casos, o Ecoturismo é tratado como turismo de baixo impacto, e que permite a reflexão no que se refere à natureza e seus recursos, além de, indiretamente, proporcionar uma reflexão acerca de sustentabilidade, hábitos cotidianos e vivência na natureza, o que se mostra revigorante para os participantes. Em termos de benefícios e sucesso, Lindberg e Hawkins (1995) consideram que:

O ecoturismo é um fenômeno complexo e multidisciplinar. Muitos aspectos devem ser levados em conta a fim de que ele seja um empreendimento bem-sucedido para todos os envolvidos: consumidores, administradores, povos nativos e fornecedores (LINDBERG; HAWKINS, 1995: p.27) 
Estas proposições lembram que o Ecoturismo faz parte de uma cadeia produtiva relacionada ao lazer e ao entretenimento, apesar do fato de que esta especificação do turismo esteja incluída no chamado Turismo Alternativo.

Assim em seu sentido geral, o turismo alternativo pode ser definido como formas de turismo que demonstram ser coerentes com os valores natural, social e comunitário e que permitem que tanto hospedeiros quando hóspedes desfrutem uma interação positiva e conveniente, e compartilhem experiências (WEARING; NEIL, 2001: p.4)

O Ecoturismo pode ser inserido dentro da categorização do Turismo Alternativo, assim como diversos outros segmentos, como o Turismo Rural, Educativo, Científico, de Aventura, entre outros. O turismo alternativo foi se dividindo de acordo com as motivações que levam os indivíduos a se deslocarem, desde o interesse na vida no campo, até esportes radicais, passando pelo interesse cultural de uma região, além de contemplar questões sobre a educação e a pesquisa científica. Porém, todas as segmentações em questão possuem alguma relação com o Ecoturismo, por terem características, finalidades, bem como motivações em comum.

Pode-se perceber a dimensão da complexidade e importância deste segmento a partir das considerações apresentadas acima. Uma vez que as divergências filosóficas, ideológicas e conceituais sobre o Ecoturismo talvez representem o tópico central a ser equacionado e pesquisado por Centros de Pesquisa no Brasil. No entanto, apesar desta lacuna, não existem centros que possam servir de referência para a produção de conhecimento ou geração de práticas desejáveis para o segmento. Este artigo visa realizar um diagnóstico sobre a produção científica em Ecoturismo no Brasil, analisar os grupos de pesquisas, suas dificuldades e oportunidades, de modo a compor um quadro de subsídios para a implementação de um Núcleo de Referência na área no câmpus Sorocaba da Universidade Federal de São Carlos (UFSCar).

Uma vez que os cursos de turismo no Brasil são ainda recentes, tiveram início na década de 1970, portanto são 39 anos apenas de atividades acadêmicas voltadas ao tema. O primeiro curso foi oferecido pela Universidade Anhembi Morumbi na cidade de São Paulo. Consequentemente ao se pensar o Ecoturismo como uma atividade relacionada ao turismo entende-se que as pesquisas nesta vertente do turismo sejam ainda mais novas.

Além do que, de acordo com o projeto pedagógico do curso de Bacharelado em Turismo da UFSCar - câmpus Sorocaba, uma vertente de grande importância e foco dentro do curso é justamente a questão da sustentabilidade, patrimônio tanto cultural como natural, Ecoturismo, planejamento de Unidades de Conservação, de forma que encaminham os estudantes para a reflexão, desenvolvimento acadêmico acerca de diversos temas correlatos e a organização de estratégias e/ou metodologias que envolvam o Ecoturismo.

Outro fator gerador de interesse pela área é de importância mundial, aliás tema 
em voga em todos os setores econômicos atualmente, que é a sustentabilidade. Uma vez considerada a importância dos aspectos pertinentes às esferas social, ambiental, econômica e política, e a conservação dos recursos naturais para a posteridade, observa-se que a temática de sustentabilidade vem ganhando a cada ano mais força e está promovendo maiores discussões dentro do meio acadêmico.

A criação de um centro de referência em Ecoturismo pode desenvolver múltiplas atividades como: oficinas, palestras, cursos, eventos, visitas orientadas, excursões, estudos do meio, entre outros, além de apresentar também uma grande variedade de finalidades: gerar e/ou disponibilizar informações e conhecimentos, propiciar o aprendizado, sensibilizar, conscientizar, motivar, integrar os atores sociais envolvidos com o Ecoturismo, propiciar a troca e a interação entre esses atores, refletir de maneira crítica a realidade e a prática do Ecoturismo, potencializar e instrumentalizar o público-alvo para a ação, investigar e pesquisar novas metodologias e estratégias de aplicação destes conceitos em áreas naturais protegidas, entre outras.

A implantação de centros de referência em pesquisa em Ecoturismo pode oferecer aos alunos instrumentos de reflexão em grupo, de aprofundamento, constituindo-se num instrumental mínimo necessário para ampliar o universo de percepções. Nesses centros será possível realizar um processo de formação conceitual, filosófica, sem se tratar de defender "a beleza do conhecimento", ou que o mesmo seja buscado de forma alienada da realidade, mas sim porque esta é uma demanda do próprio mercado, principalmente para as funções de planejamento e gerenciais.

Com pesquisas de ponta, será possível elevar o nível do debate nos cursos, o que permite um olhar mais alto sobre todo o cenário, que não desconsidera o mercado, mas permite uma visão crítica, mais profunda que hoje é uma demanda importante.

A partir destas considerações, a pesquisa realizada visou identificar os principais grupos de estudos de Ecoturismo no Brasil a partir de questionários aplicados aos autores dos resumos de trabalhos enviados ao III Encontro Interdisciplinar de Ecoturismo em Unidades de Conservação (ECOUC) e VII Congresso Nacional de Ecoturismo (CONECOTUR), realizado em novembro de 2009, no Estado do Espírito Santo. Este levantamento visou identificar os principais focos dos grupos de pesquisa em questão, avaliar as questões de fomento, de linhas de pesquisa, distribuição no Brasil, as publicações que são feitas por estes grupos de pesquisas, verificar nesta edição a participação dos grupos previamente levantados, entre outros.

\section{Metodologia}

Foi efetuado um estudo sobre os grupos de pesquisa aos quais os trabalhos aprovados no ECOUC estão vinculados. Através da análise dos dados inventariados previamente, bem como da aplicação de questionário fechado, enviado por e-mail, o mesmo para todos os autores dos resumos e trabalhos aprovados para esta edição do evento, foram elaboradas análises qualitativas (em forma de tabelas - Anexo 1) e 
quantitativas (em forma de gráficos), para a interpretação dos resultados e "estado da arte" no que se refere aos grupos de estudos de ecoturismo, vinculados a um órgão de agência de fomento.

Após o recebimento das respostas, os questionários foram separados entre os trabalhos que estavam vinculados a um grupo de pesquisa e os trabalhos que não eram vinculados a grupo de pesquisa.

Os dados dos questionários foram compilados, tabulados e posteriormente foram elaborados gráficos para melhor compreensão e visualização dos resultados dos questionários. Foi elaborado o Anexo1 que mostra maiores detalhes a respeito dos grupos encontrados.

\section{Resultados e discussão}

O Anexo 1 apresenta os dados dos grupos de pesquisas vinculados aos órgãos de fomento ${ }^{1}$. Ao todo foram incorporados aos grupos previamente encontrados outros 22 novos grupos, de diferentes instituições, com linhas de pesquisa e objetivos diversos.

Foram enviados 192 trabalhos para o Congresso, e obtidas como resposta ao questionário enviado 120 e-mails, apresentando um total de 136 trabalhos. Em alguns casos, os participantes e autores dos trabalhos não responderam a todos os itens dos formulários.

Os grupos possuem em sua maioria, temas de pesquisa: Ecoturismo, planejamento e gestão da atividade a fim de encontrar meios mais sustentáveis para utilização de recursos naturais, atividades de percepção ambiental com o intuito de conservação e educação ambiental, análise de impactos e monitoramento da atividade. Ao todo foram encontrados 38 grupos de pesquisa, porém 2 não divulgaram nenhuma informação a respeito do grupo, somente o nome. No caso dos levantamentos qualiquantitativos, na maioria dos casos será levado em conta o número de 36 grupos. Em alguns casos, alguns dados coletados na atual pesquisa não foram solicitados na pesquisa anterior, o que gerou aqui uma defasagem em termos de quantidade em alguns itens do questionário.

Em termos de distribuição territorial dos grupos detectados, foi diagnosticada na pesquisa anterior, uma porcentagem relativamente semelhante para as regiões Nordeste e Sul (com 13\% cada), bem como entre Norte e Sudeste (com 34\% cada), possuindo a menor porcentagem, a região Centro - Oeste (com $7 \%$ apenas). Já em relação a 2009, pode-se observar um aumento no número de grupos, e consequentemente uma diferença no que se refere à sua distribuição. A Figura 1 apresenta a distribuição em porcentagem dos grupos de pesquisa em Ecoturismo nas regiões brasileiras: 


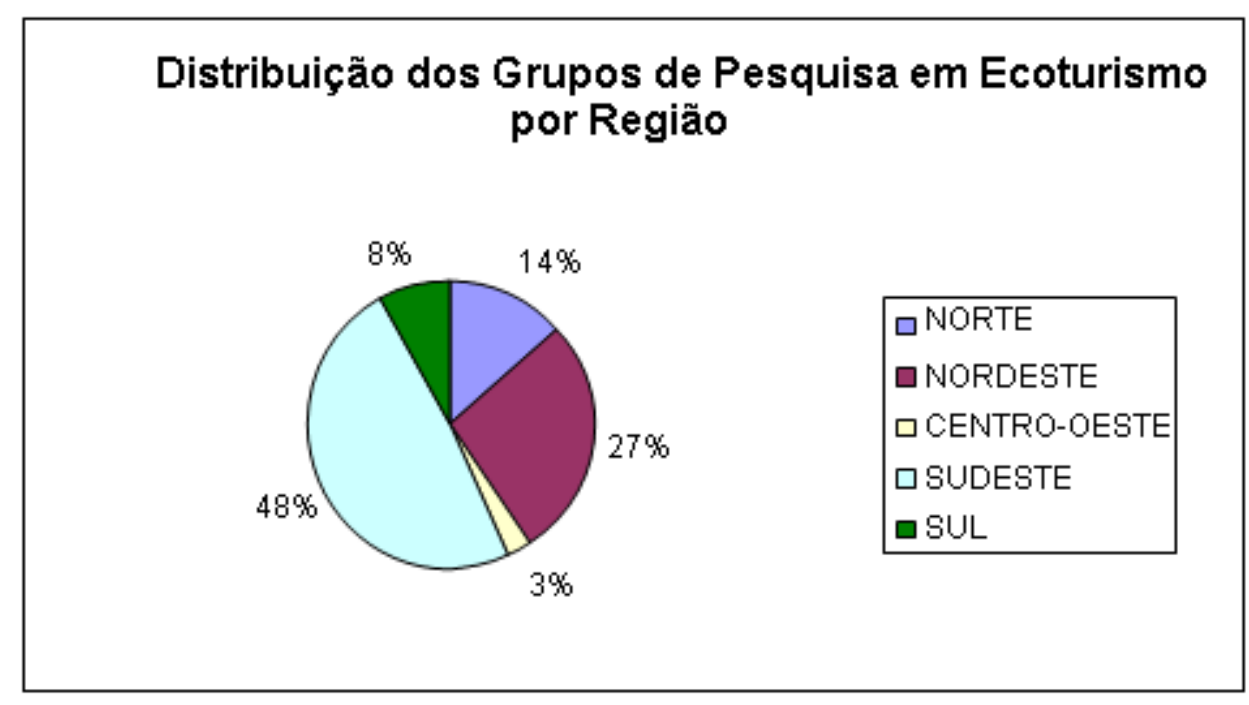

Figura 1 - Quantidade de Grupos de Pesquisa em Ecoturismo por Região.

Neste segundo levantamento, foi detectado que houve um aumento no número dos grupos de pesquisa em Ecoturismo na região Sudeste, com $48 \%$ de 36 grupos totais, seguida da Região Nordeste, com $27 \%$, precedida pela região Norte, com $14 \%$ e as regiões Sul, com $8 \%$ e a Região Centro-Oeste, com 3\% apenas.

Verificou-se na pesquisa preliminar que $60 \%$ do total dos 16 grupos apresentados se encontram em universidades públicas, das quais cinco são estaduais (UERN, UESPI, UNESP, UERJ, UEPG) e quatro federais (UFMA, UFBA, UFMT, UFSCar); $20 \%$ dos grupos de pesquisa em Ecoturismo se encontram em Institutos (IDSM-OS, INPA, IF); 13\% dos grupos de pesquisa em Ecoturismo estão em universidades privadas (UCP, UNIDAVI) e $7 \%$ estão em centros tecnológicos (CEFET/S).

Já no presente levantamento, $65 \%$ do total dos 36 grupos apresentados se encontram em universidades públicas, $16 \%$ dos grupos de pesquisa em Ecoturismo se encontram em Institutos, $16 \%$ dos grupos de pesquisa estão em universidades privadas e $3 \%$ estão em centros tecnológicos (CEFET/S) apenas (Figura 2). Desta forma, pode-se avaliar que no contexto das universidades, aquelas da rede pública demonstram maior interesse em questões ambientais, no que concerne ao Ecoturismo, definições e práticas, à produção acadêmica e discussão do tema, uma vez que, a partir do gráfico acima é verificado que $65 \%$ do total das instituições que abrigam os grupos são as universidades públicas do país. 


\section{Tipos de Intituições que abrigam os Centros e Grupos de Pesquisa em Ecoturismo}

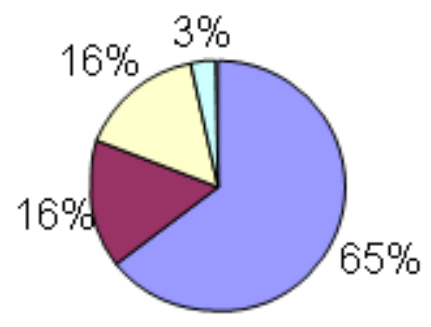

口 UNIVERSIDADES

PÚBLICAS

口UNIVERSIDADES

PRIVADAS

口INSTITUTOS

$\square$ CENTRO

TECNOLÓGICOS

Figura 2 - Tipos de Instituição que abrigam os Grupos de Ecoturismo.

$\mathrm{Na}$ pesquisa preliminar, foram encontrados 16 grupos que responderam aos questionários, e que forneceram as informações. Já no caso do levantamento feito no EcoUC, foram detectados 4 grupos de pesquisa em Ecoturismo que são comuns aos dessa fase anterior. São eles: O Grupo de Estudos Ambientais, o Grupo Ecoturismo e Educação, Núcleo de Estudos de Turismo Sustentável, e o GRUTAS - Grupo de Pesquisa em Turismo de Aventura e Sustentabilidade. Desta forma, é possível considerar que esses Grupos, no período desta pesquisa, continuam ativos, de forma que possuem produção acadêmica recente (resumos, livros, artigos) publicada nos últimos 5 anos (Figura 3).

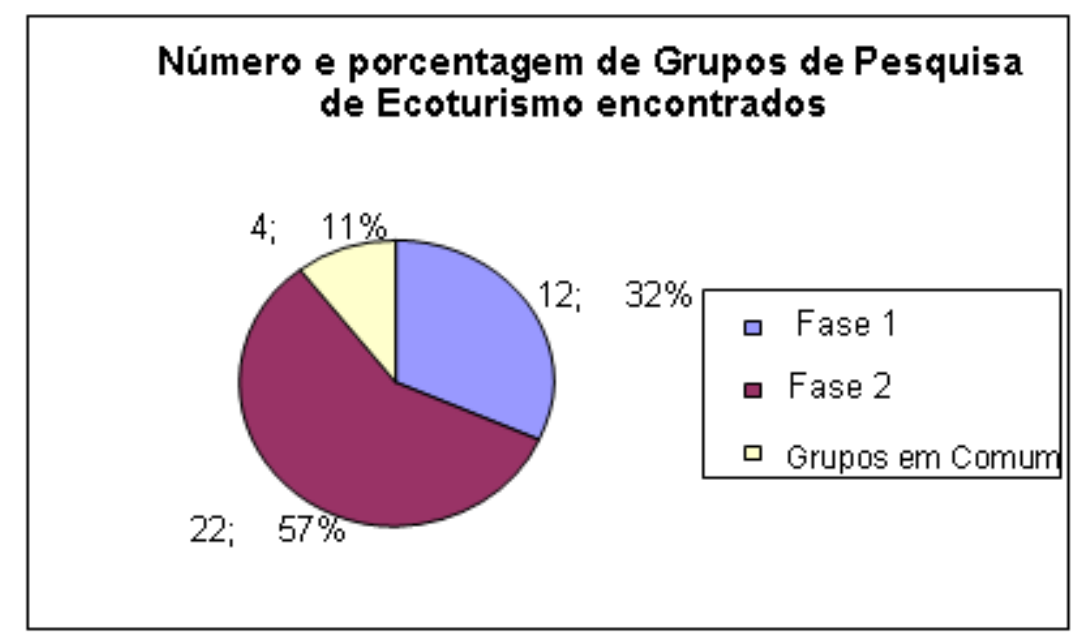

Figura 3 - Número e porcentagem de Grupos de Pesquisa de Ecoturismo encontrados. 
A Figura 4 demonstra a somatória total dos trabalhos publicados de 16 grupos. Os outros 22 grupos não divulgaram a informação, que pode ser devido ao fato de terem sido criados recentemente, ou simplesmente por não terem produção nos últimos cinco anos.

\section{Número Total de Publicações dos Grupos de Pesquisa nos últimos 5 anos}
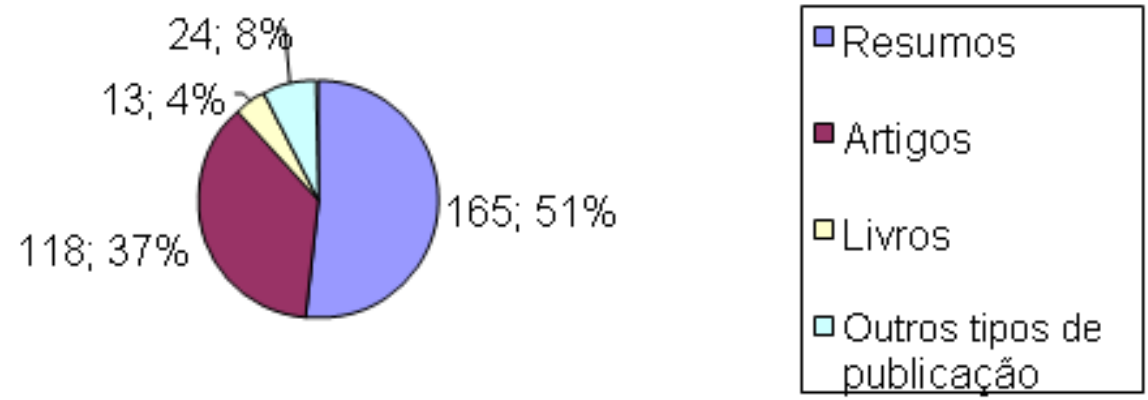

Figura 4 - Número Total de Publicações dos Grupos de Pesquisa nos últimos 5 anos.

A Figura 5 ilustra o ano de formação de 35 grupos de Pesquisa em Ecoturismo, considerando que os Grupos: Comunidades Sustentáveis, Arqueologia e Patrimônio no Baixo Amazonas e Sistema de Informações Ambientais para o Desenvolvimento Sustentável não divulgaram estas informações através dos questionários. Pode-se verificar a maior incidência do início da maioria dos grupos a partir de 2006, o que pode ser relacionando diretamente à importância do tema da sustentabilidade não somente no meio acadêmico como na mídia nos últimos anos.

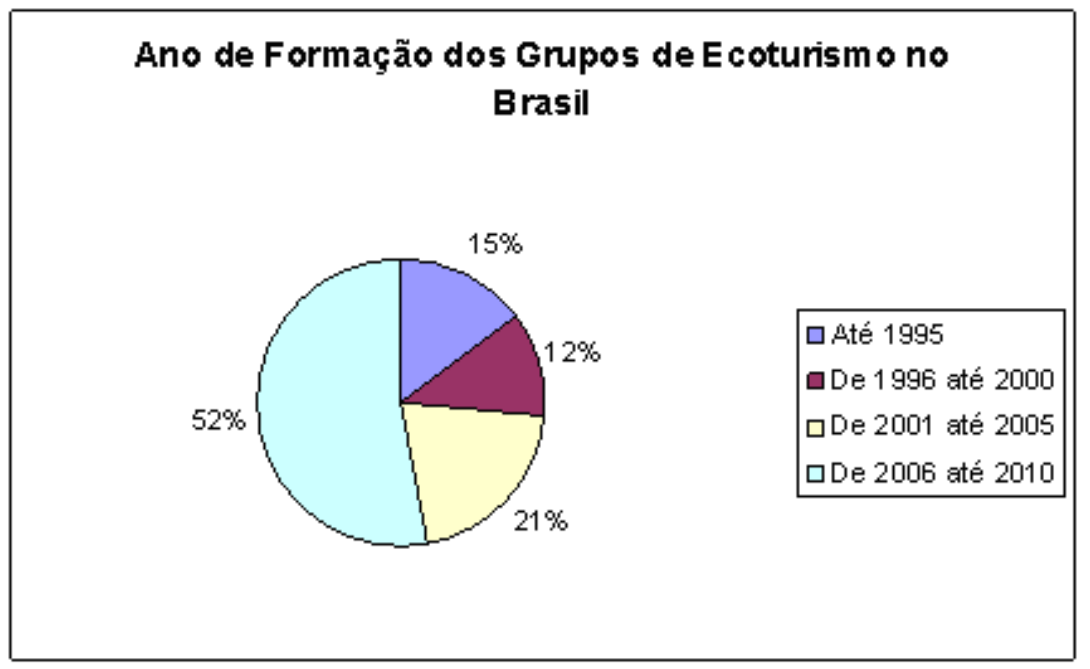

Figura 5 - Ano de formação dos Grupos de Ecoturismo no Brasil. 
Além da preocupação ambiental que muitas vezes está relacionada ao desmatamento de áreas protegidas, a temática do desperdício de recursos naturais, os problemas relacionados aos modos da vida cotidiana, e questões como o turismo implementado de maneira equivocada, a inserção da comunidade local na atividade turística, entre muitos outros; podem ser motivos para a criação de grupos de estudo sobre o Ecoturismo, que envolve diversos aspectos que devem ser estudados para a melhoria do ramo.

Os oito grupos de pesquisa que possuem algum trabalho que teve financiamento (Figura 6) e as respectivas organizações, ou agências de fomento que foram encontrados nos formulários compilados são: "Turismo e Cultura: Gestão e Desenvolvimento Sustentável" (NZAID); "Sujeitos da educação: Cultura e Construção da Identidade" (PIBIC - IFPE); "Espaço e Meio Ambiente" (FAPEMIG); "GRUTAS - Grupo de Pesquisa em Turismo de Aventura e Sustentabilidade" (FAPESP); "Geoturismo e Geoparques" (PROJETO TAMAR); "NEATUS" (CAPES); "Grupo de Estudo Ambientais (GEA)" (FAPERJ e IPGH); e "Sociedade e Meio Ambiente", que não divulgou a agência de fomento. Os Grupos GRUTAS e GEA também possuem trabalhos que não foram financiados por agência de fomento. O Órgão NZAID é proveniente da Nova Zelândia, que beneficia um grupo, cujo líder é brasileiro.

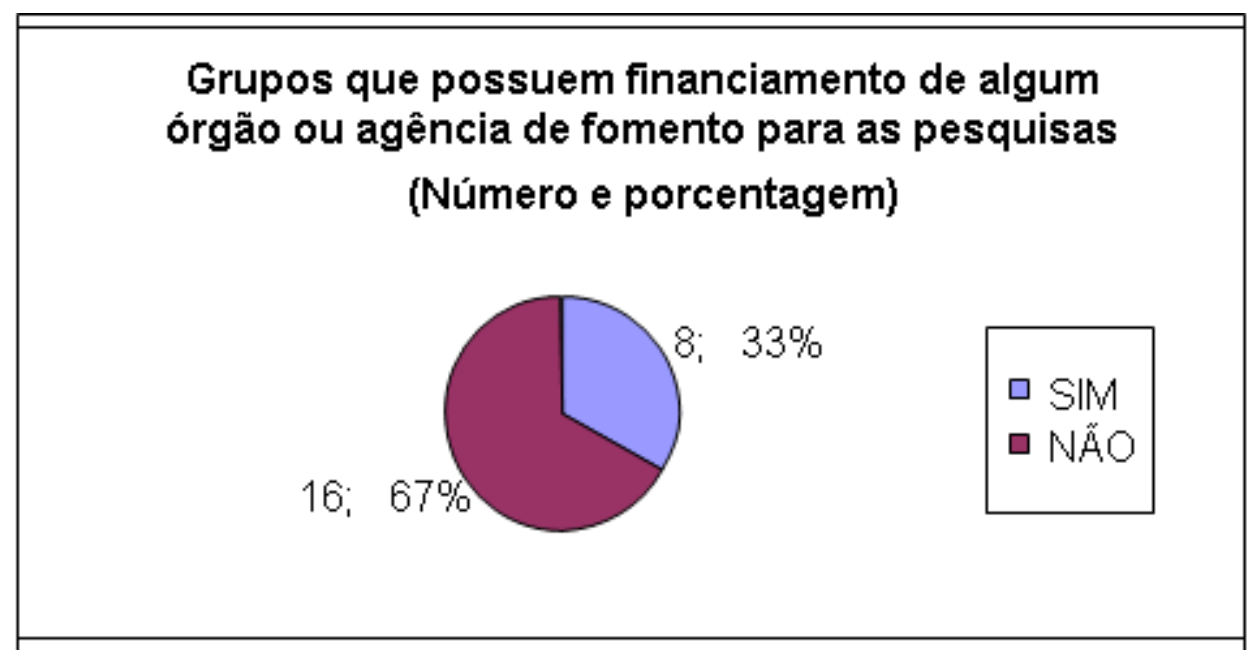

Figura 6 - Grupos de Pesquisa que possuem financiamento para as pesquisas.

A Figura 7 é referente ao número de pesquisadores, entre professores doutores, alunos de pós-graduação, alunos de graduação e outros. Neste levantamento, 17 grupos não se manifestaram quanto aos pesquisadores que compõem o grupo. 


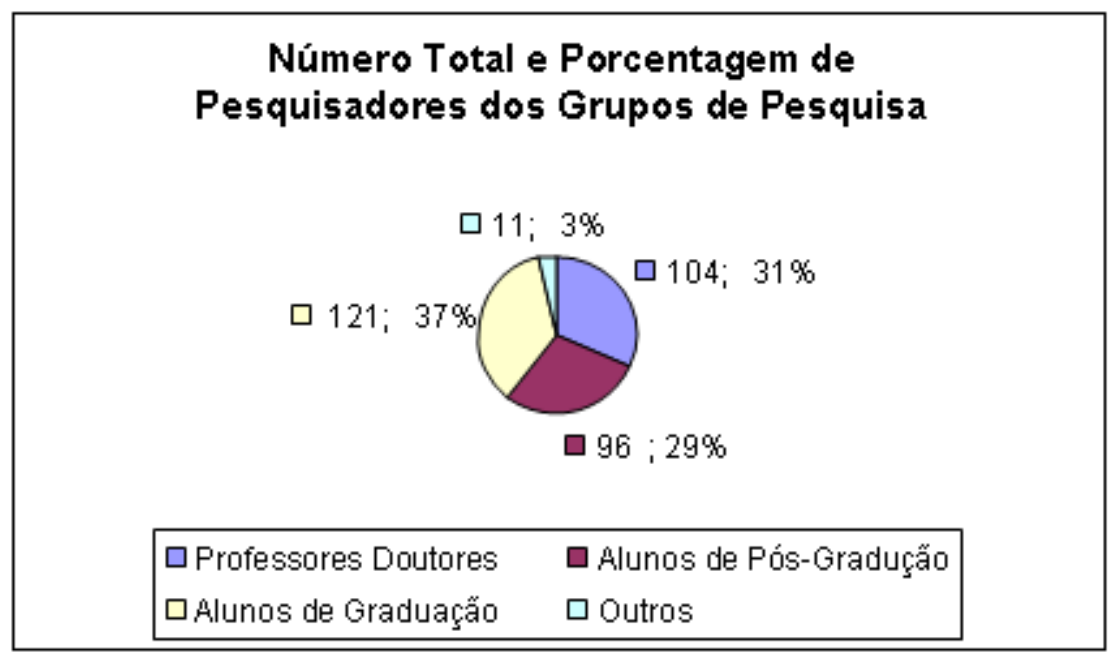

Figura 7 - Número total e porcentagem dos Pesquisadores dos Grupos.

É possível notar que as porcentagens totais são próximas, o que permite afirmar que, de modo geral, tanto os professores como os alunos possuem semelhante abertura para a participação nos grupos. É interessante perceber que, nos números totais, há mais estudantes de graduação, o que demonstra um interesse crescente no que se refere ao tema Ecoturismo e suas vertentes nesse segmento.

$\mathrm{Na}$ elaboração da Figura 8, foram levadas em conta as respostas de 20 grupos a respeito de publicações próprias.

\section{Número e Porcentagem de Grupos de Ecoturismo que possuem Publicação Própria}

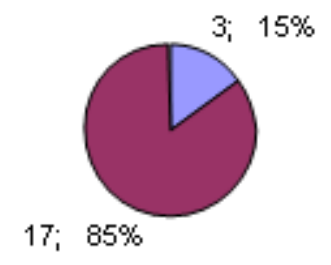

$$
\begin{aligned}
& \square \text { SIM } \\
& \square \quad N A O
\end{aligned}
$$

Figura 8 - Número e Porcentagem de Grupos que possuem Publicação Própria.

Os outros 18 grupos não se manifestaram neste tópico do formulário. Os três grupos que responderam afirmativamente são:

- Grupo AgroFlorestal - GRAF;

- Grupo de Estudo de Lazer e Cultura;

- Biodiversidade, Áreas Protegias e Inclusão Social. 
Já o grupo "Biodiversidade, Áreas Protegidas e Inclusão Social" não divulgou o nome nem a natureza da publicação.

Considerando o universo de 24 grupos de pesquisa que responderem à pergunta referente à participação em redes (Figura 9), as porcentagens são: $54 \%$ dos grupos participam de redes, enquanto que $46 \%$ não participam.

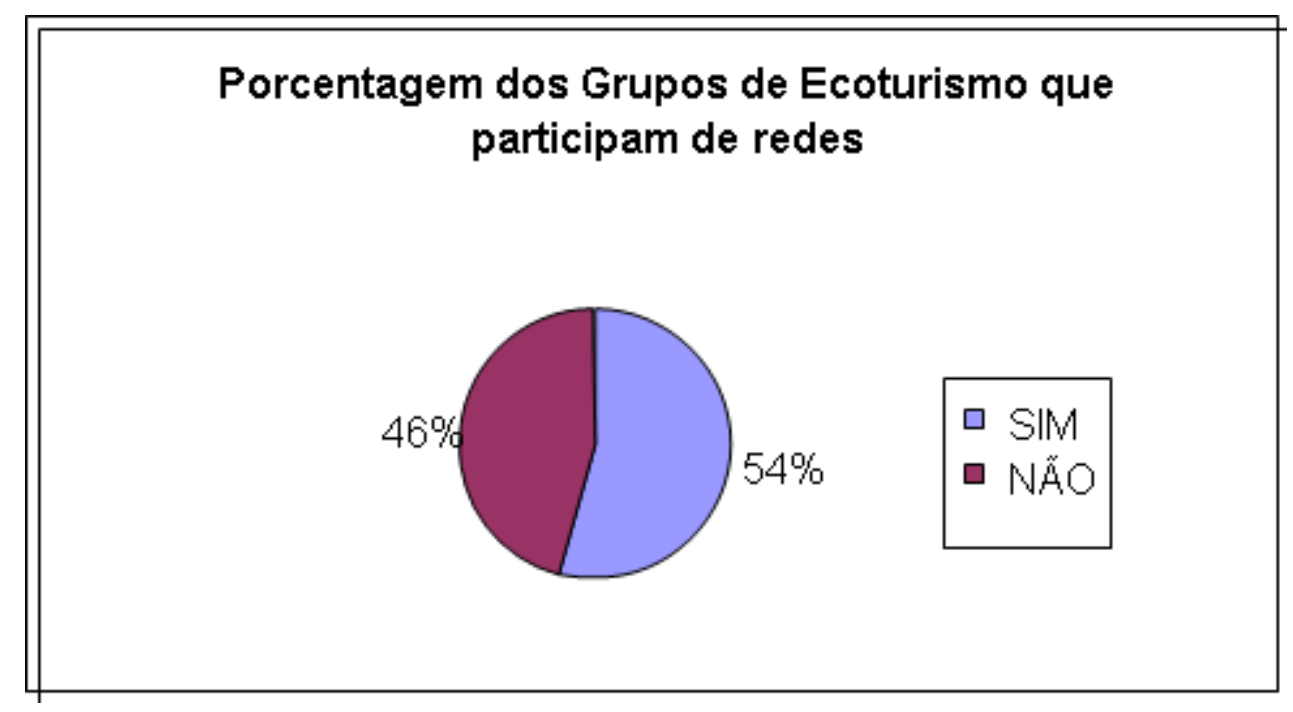

Figura 9 - Porcentagem dos Grupos de Ecoturismo que participam de Redes.

As redes, nessa questão foram designadas das mais diversas formas. Segue abaixo a lista das redes citadas:

- REDE SOCIOAMBIENTAL APA SUL RMBH;

- Rede Municipal de Educação Ambiental (REMEA);

- GT de Questões Socioambientais Urbanas da Associação Nacional de Programas de Pós-Graduação em Geografia (ANPEGE);

- REDE BRASILEIRA DE ECOTURISMO (RBE);

- Red Virtual de Areas Protegidas de Latinoamerica;

- REBEA;

- FBOMS;

- Grupo Virtual de Discussão sobre o Lazer;

- Ecoturismo;

- Anptur;

- CBTS;

- Rede Cerrado;

- Orkut;

- Facebook;

- REDENET; 
- Rede Agenda 21 do Grande ABC;;

- Coletivo Jovem de Meio Ambiente do Grande ABC;

- Coletivo Jovem de Meio Ambiente de Belo Horizonte;

- CJMG;

- REJUMA;

- REBEA.

Em relação à continuidade dos trabalhos apresentados no III EcoUC e VII CONECOTUR pelos integrantes dos grupos de pesquisa, somente $5 \%$ não terá continuidade (Figura 10).

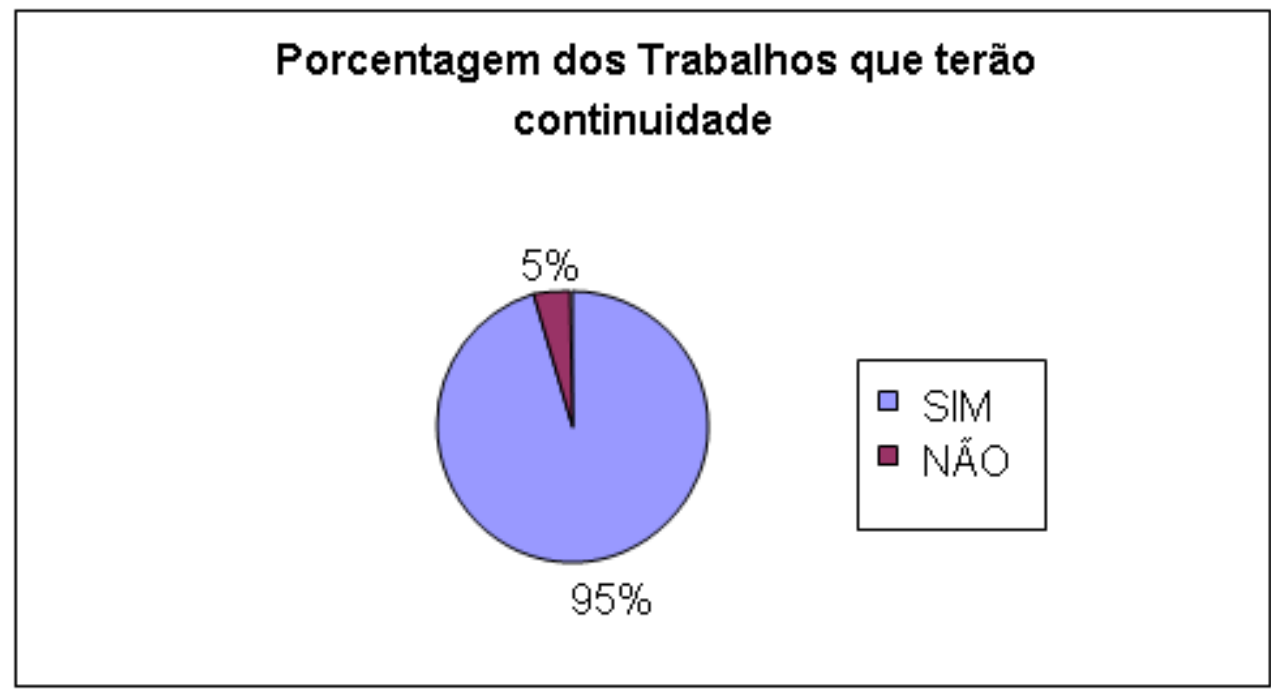

Figura 10 - Porcentagem de Trabalhos apresentados que terão continuidade e estão vinculados a Grupos de Pesquisa

Os $95 \%$ dos trabalhos que terão continuidade, serão realizados através de distintas formas, como ilustra a Figura 11.

Analisando-se a Figura 11, é possível perceber que muitas das pesquisas apresentadas no Congresso Nacional de Ecoturismo são provenientes ou precursoras de outras pesquisas. No caso, $43 \%$ dos trabalhos resultarão em novas pesquisas, seja devido à necessidade de aprofundar a metodologia, outra abordagem, ou até um mesmo foco; $21 \%$ do total das pesquisas serão utilizadas em Trabalhos de Conclusão de Curso de Graduação; $10 \%$ do total será para Trabalho de Conclusão de Curso de Pós-Graduação bem como os outros $10 \%$ dos trabalhos serão utilizados para a Tese de Doutorado, e $8 \%$ dos trabalhos terão continuidade como Dissertação de Mestrado e os outros $8 \%$ serão relativas a outros tipos de pesquisa ou aplicação prática do projeto, entre outras possibilidades. No formulário havia a opção: Trabalho de PósDoutorado, que não obteve nenhuma resposta. 
Neiman, Z.; Saraceni, R.F.; Geerdink, S.

\section{Tipos de Trabalhos que darão continuidade aos trabalhos apresentados}

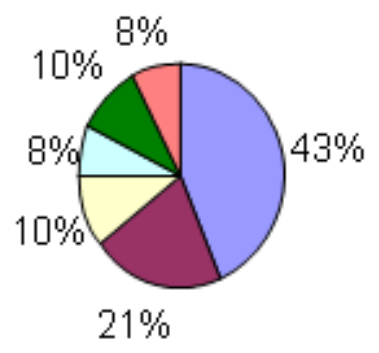

-Novas Pesquisas

- Trabalho de Conclusã̃o de Curso de Graduaçẫo

口Trabalho de Conclusẫo de Curso de Pós-Graduaçẫo

口Dissertaçẫo de Mestrado

- Tese de Doutorado

口 Outros

Figura 11 - Tipos de Trabalhos que darão continuidade aos trabalhos apresentados e vinculados a Grupos de Pesquisa

Em relação à divulgação e conhecimento dos grupos de pesquisa, um dos itens do formulário foi a respeito da existência de um website para consulta de trabalhos e divulgação das atividades desenvolvidas. A porcentagem de $64 \%$ dos 20 grupos que responderam a este item disse que não possuía um website. Já os $36 \%$ restantes responderam afirmativamente (Figura 12).

Seguem abaixo os Grupos de Pesquisa com website:

- Geoturismo e Geoparques;

- GRAF - Grupo Agroflorestal;

- GRUTAS;

- Turismo e Cultura: Gestão e Desenvolvimento Sustentável;

- NEATUs;

- Paisagem, Cultura e Sociedade;

- SIADES;

- Unidade Interdisciplinar de Estudos sobre a Habitação e o Espaço Construído. 


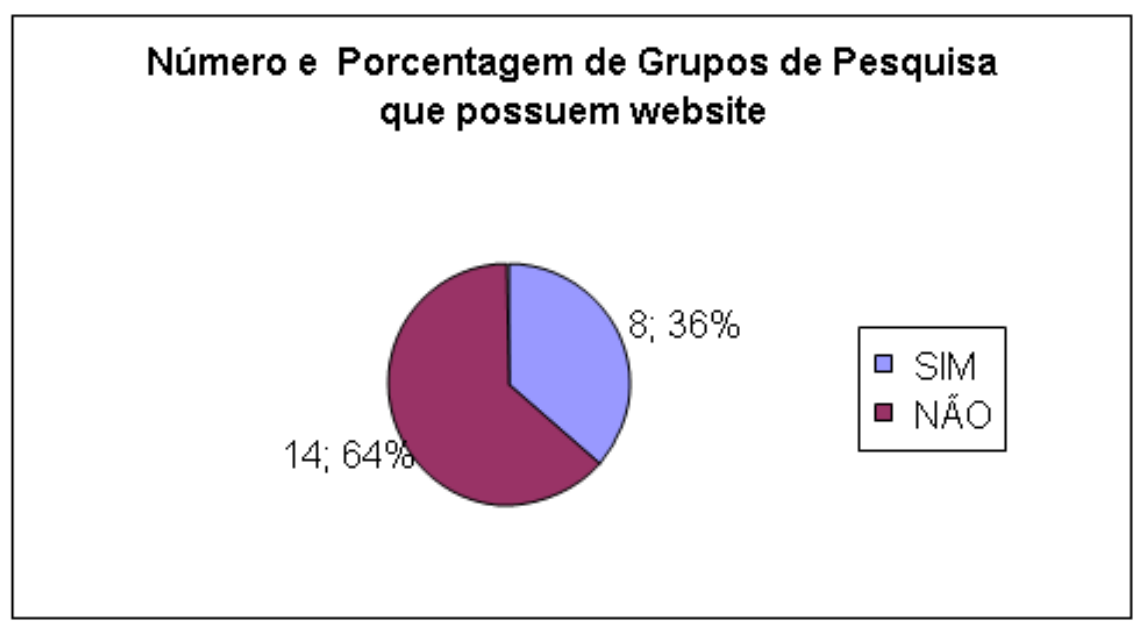

Figura 12 - Número e Porcentagem dos Grupos de Pesquisa que possuem website.

Em relação ao total de trabalhos que foram aceitos no $\mathrm{III}^{\circ} \mathrm{EcoUC}$ e no $\mathrm{VII}{ }^{\circ} \mathrm{CO}-$ NECOTUR, foi aplicado o mesmo questionário para todos, de forma a verificar a existência de um grupo de estudos em Ecoturismo e a eventual existência de financiamento dos trabalhos e quais os órgãos de fomento, Verificou-se também se haveria continuidade destes trabalhos.

A Figura 13 apresenta a porcentagem dos trabalhos apresentados no III EcoUC e no VII CONECOTUR que estão vinculados a grupos de pesquisa ou não.

Dos 136 trabalhos apresentados a compilados na pesquisa desta edição do evento, $26 \%$ dos trabalhos estão vinculados a grupos de pesquisa de Ecoturismo formalizados, já $74 \%$ dos trabalhos não estão vinculados a Grupos, uma vez que alguns estão relacionados às pesquisas para o Trabalho de Conclusão de Curso de Graduação ou Pós-Graduação, ou então relacionados à Projetos de Iniciação Científica, entre outros.

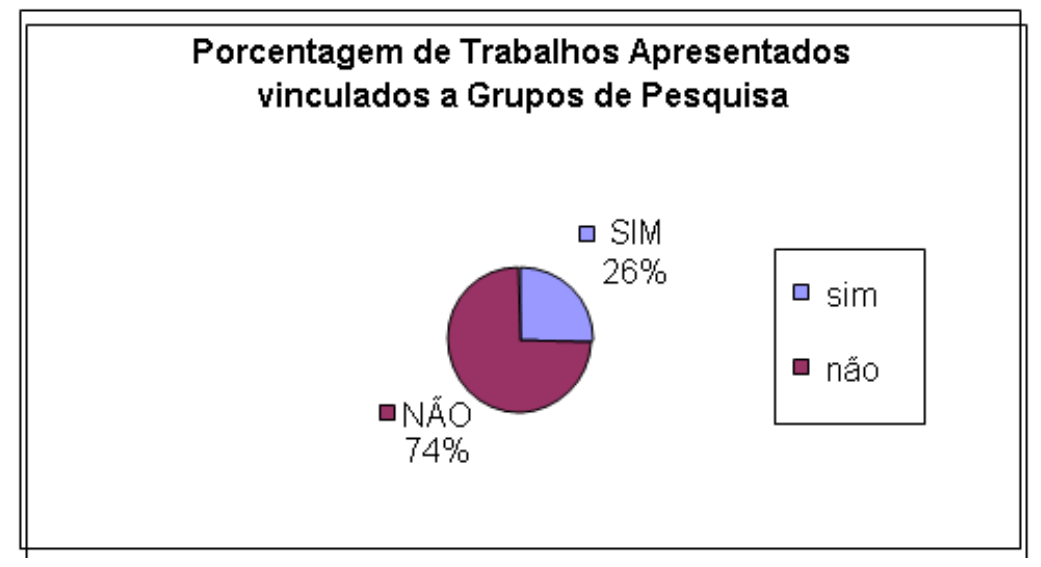

Figura 13 - Porcentagem dos Trabalhos Apresentados vinculados a Grupos de Pesquisa. 
Do total de 136 trabalhos apresentados, 83\% não recebem financiamento algum e $17 \%$ recebem financiamento de algum órgão de fomento, seja nacional ou internacional (Figura 14).

\section{Porcentagem de trabalhos aceitos no III ECOUC e VII CONECOTUR que receberam financiamento}

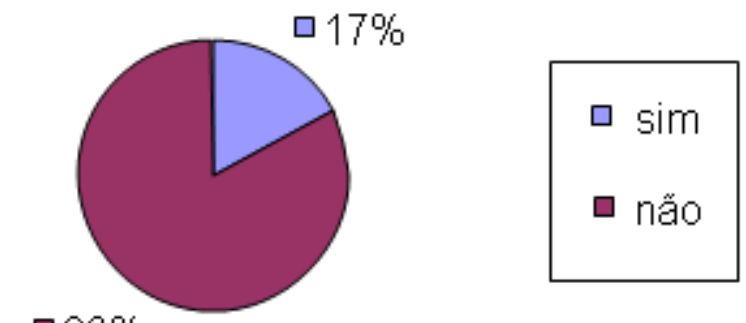

$\square 83 \%$

Figura 14 - Porcentagem dos Trabalhos aceitos no III ECOUC e no VII CONECOTUR que recebem financiamento.

Neste caso, 14 grupos de pesquisa não se manifestaram a respeito deste tópico, uma vez que não possuíam trabalhos nesta edição do evento. Segue abaixo a listagem dos órgãos de fomento encontrados:

- Banco Mundial;

- GreenGrants;

- Fondo de las Américas;

- Programa de Pequeñas Donaciones;

- PIBITI;

- $\mathrm{CNPq}$

- PIBIC;

- FAPESP;

- IF Fluminense;

- Edital 2008/2009EDP- Energias do Brasil;

- FAPESB;

- PROGRAMA DAS NAÇÕES UNIDAS PARA O DESENVOLVIMENTO PNUD / PROJETO CORREDORES ECOLÓGICOS (PCE/BA);

- Prefeitura de Descalvado;

- PDA; 
- PRODETUR;

- USAID;

- NZAID;

- Pró-reitoria de Graduação da Universidade de São Paulo - Iniciação Científica

- FAPEMIG;

- Secretaria de Estado de Meio Ambiente do Pará (SEMA-PA) - Fundo Estadual de Meio Ambiente (FEMA);

- ONG Instituto Terra de Preservação Ambiental;

- Prefeitura Municipal de Paracambi (Secretaria de Meio Ambiente).

Os órgãos de fomento à pesquisa que apareceram mais de uma vez são: a FAPESP (com financiamento de 2 trabalhos), a FAPERJ (com o financiamento de 4 trabalhos), CNPq (com financiamento de 2 trabalhos), e a FAPEMIG, (com financiamento de 2 trabalhos).

A Figura 15 ilustra as porcentagens dos trabalhos que terão continuidade.

Em relação ao numero total de trabalhos, considerando os trabalhos vinculados a grupos e os trabalhos enviados sem vínculo a grupo, o percentual de trabalho que terão continuidade é de $88 \%$ enquanto os trabalhos que não terão continuidade somam 12\%. Neste item, foram 22 grupos considerados, uma vez que os 16 da Fase 1 não responderam ao tópico. De um total de 133 trabalhos vinculados aos grupos, haverá diversas formas de continuidade (Figura 16).

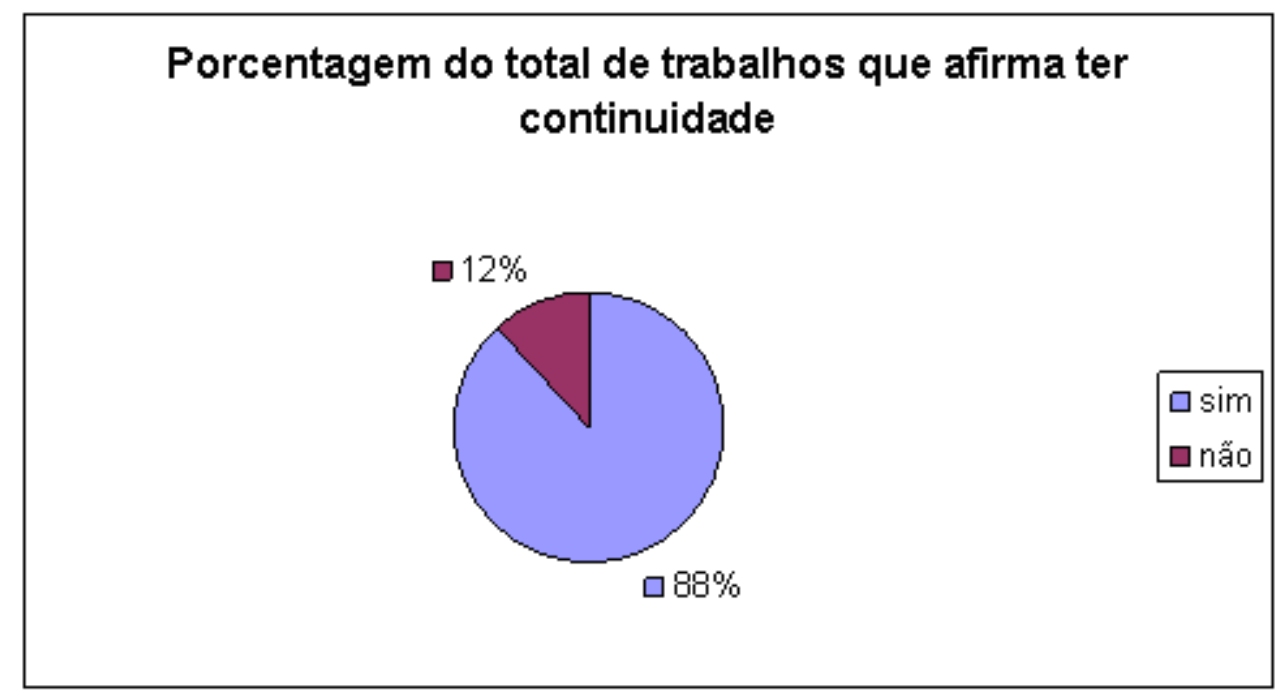

Figura 15 - Porcentagem do total de Trabalhos que afirma ter continuidade. 
Neiman, Z.; Saraceni, R.F.; Geerdink, S.

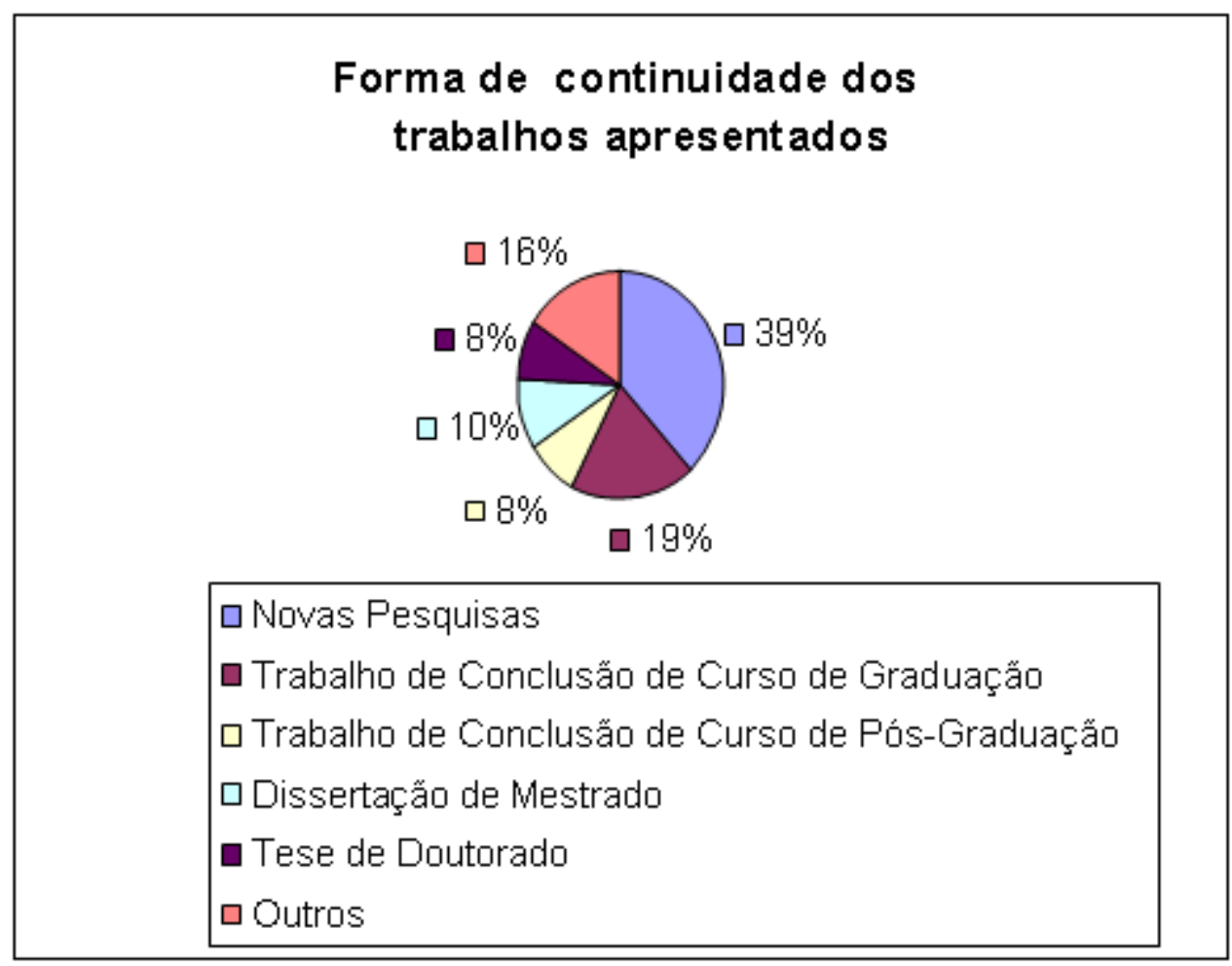

Figura 16 - Formas de continuidade dos trabalhos apresentados.

Ainda considerando a mesma proporção anterior em relação a número de trabalhos vinculados a grupos de pesquisa e aqueles que não possuem vínculo a grupos de pesquisa, a maioria dos trabalhos terá continuidade através de Novas Pesquisas, que corresponde a $39 \%$, seguida de 19\%, que está relacionado a Trabalhos de Conclusão de Curso de Graduação, posteriormente 16\%, que representa a categoria Outros, que pode significar a aplicação prática do projeto apresentado, projetos práticos e de implementação da teoria explicitada, entre outros. $10 \%$ da continuação dos trabalhos apresentados será em relação a Dissertação de Mestrado, e $8 \%$ será para Trabalho de Conclusão de Curso de Pós Graduação e outros 8\% será para Tese de Doutorado. Havia ainda, o item Trabalho de Pós-Doutorado, porém não houve resposta.

\section{Considerações finais}

Foi possível averiguar que a maioria dos Grupos de Pesquisa em que direta ou indiretamente investigam o Ecoturismo é recente, sendo constituídos há poucos anos, e ainda não possuem número relevante de publicações. Há exceções, pois alguns grupos vêm se destacando e hoje são referência no Brasil, em termos de pesquisa e discussão sobre o tema. Porém é estimulante perceber que as universidades, tanto as 
Levantamento quali-quantitativo da produção científica sobre Ecoturismo no Brasil.

públicas quanto as privadas, se interessam e dão valor ao tema do Ecoturismo e seus desdobramentos (comunidades, educação, conservação, impacto) de forma a discutir as questões teóricas da atividade, para que melhorias possam ser implementadas, em um futuro próximo. A próxima fase deste estudo será a avaliação mais ampla sobre a situação do aporte (apoio) dos órgãos de fomento brasileiros às pesquisas desenvolvidas pelos grupos e como vem sendo desenvolvidos no Brasil (tanto aquelas em andamento como as que foram finalizadas com sucesso), assim como todos os trabalhos acadêmicos (graduação e pós) que já foram desenvolvidos no Brasil (defendidos ou em vias de defesa).

\section{Referências Biliográficas}

BRANDON, K. Etapas Básicas para Incentivar a Participação Local em Projetos de Turismo voltado para a Natureza. 2002. In: LINDBERG, K., HAWKINS, D. E. (orgs). Ecoturismo: Um Guia para Planejamento e Gestão. São Paulo: Editora SENAC, 2002. Pp. 225-252.;

COSTA, N.C.; NEIMAN, Z.; COSTA, V. Pelas trilhas do Ecoturismo. São Carlos: Ed. RiMa, 2008;

DIEGUES, Antônio Carlos (org.). Etnoconservação: Novos Rumos para a Conservação da Natureza. São Paulo: Hucitec-NUPAUB-USP, 2000.

Diretrizes para uma Política Nacional de Ecoturismo. Coordenação de Sílvio Magalhães e D. Hamú M. de la Penha. Brasília,1994.

LINDBERG, K.; HAWKINS, D. (eds.). Ecoturismo: um guia para o planejamento e gestão. São Paulo, SENAC, 1995.

MIECZKOWSKI, Z. Environmental issues of tourism and recreation. Lantarn, Maryland: University Press of America, Inc, 1995.

NEIMAN, Z. \& MENDONÇA, R. Ecoturismo no Brasil. Barueri: Manole, 2004;

ORGANIZAÇÃO MUNDIAL DE TURISMO. Guia de desenvolvimento do turismo sustentável. Sandra Netz (Trad.). Porto Alegre: Bookman, 2003.;

PELEGRINI FILHO, A. Ecologia, cultura e turismo. Campinas: Papirus, 1993.;

SERRANO,C. O “produto” ecoturístico. In: ANSARAH, M. G. R. (Org.). Turismo: como aprender, como ensinar. São Paulo: SENAC, 2000, p. 203-234.

SWARBROOKE, J. Turismo sustentável: conceitos e impacto ambiental. Margarete Dias Pulido (Trad.). 3 ed. São Paulo: Aleph, 2000.(volume 1 a 5);

WEARING, S., NEIL, J. Ecoturismo: Impactos, Potencialidades e Possibilidades. Barueri: Manole, 2001. 
${ }^{1}$ Nota: Os grupos Comunidades Sustentáveis e Arqueologia e Patrimônio no Baixo Amazonas não responderam ao questionário. somente foi divulgado o nome do grupo.

Zysman Neiman: Universidade Federal de São Carlos, Laboratório de Ecoturismo, Percepção e Educação Ambiental (LEPEA).

Email: zysman@physis.org.br

Link para o currículo Lattes: http://lattes.cnpq.br/6435341856481082

Renata Fronza Saraceni: Universidade Federal de São Carlos, Laboratório de Ecoturismo, Percepção e Educação Ambiental (LEPEA).

Email: refronza_tur@yahoo.com.br

Link para o currículo Lattes: http://lattes.cnpq.br/0139068179469647

Stefanie Geerdink: Universidade Federal de São Carlos, Laboratório de Ecoturismo, Percepção e Educação Ambiental (LEPEA).

Email: stefa_pivah@yahoo.com.br

Link para o currículo Lattes: http://lattes.cnpq.br/1652236279503612

Data de submissão: 24 de abril de 2010.

Data do aceite: 25 de junho de 2010. 


\begin{tabular}{|c|c|c|c|c|c|c|}
\hline$\underset{0}{N}$ & Instituição & $\begin{array}{l}\text { Grupo de } \\
\text { Pesquisa }\end{array}$ & Linhas de pesquisa & Pesquisadores líderes & $\begin{array}{l}\text { Ano de } \\
\text { Formação }\end{array}$ & Objetivos \\
\hline 1 & $\begin{array}{c}\text { Centro Federal de } \\
\text { Educação Tecnoló- } \\
\text { gica de Sergipe - } \\
\text { CEFET/S }\end{array}$ & $\begin{array}{c}\text { Educação e Ecoturis- } \\
\text { mo }\end{array}$ & $\begin{array}{l}\text { Educação, Ecoturis- } \\
\text { mo, Educação Ambi- } \\
\text { ental e Turismo }\end{array}$ & $\begin{array}{l}\text { Ana Karina de Oliveira } \\
\text { Nascimento } \\
\text { José Carlos Santos } \\
\text { Cunha } \\
\text { Claudio Roberto Bra- } \\
\text { ghini }\end{array}$ & 2007 & $\begin{array}{l}\text { Promover a discussão dos } \\
\text { princípios do ecoturismo e } \\
\text { suas aplicações na educa- } \\
\text { ção, Desenvolver pesquisa } \\
\text { e extensão nas áreas de } \\
\text { Educação e Ecoturismo }\end{array}$ \\
\hline 2 & $\begin{array}{l}\text { Universidade do } \\
\text { Estado do Rio Gran- } \\
\text { de do Norte - UERN }\end{array}$ & $\begin{array}{c}\text { Gestão e Planeja- } \\
\text { mento Sustentável } \\
\text { do Turismo }\end{array}$ & $\begin{array}{c}\text { Ecoturismo e Desen- } \\
\text { volvimento Sustentá- } \\
\text { vel }\end{array}$ & $\begin{array}{l}\text { Antonio Jânio Fernan- } \\
\text { des } \\
\text { Sidcley D'sordi Alves } \\
\text { Alegrini da Silva }\end{array}$ & 2006 & $\begin{array}{l}\text { Promover ações que levem } \\
\text { a identificar e proporcionar } \\
\text { atividades de gestão e pla- } \\
\text { nejamento sustentável dos } \\
\text { recursos naturais do RN }\end{array}$ \\
\hline 3 & $\begin{array}{c}\text { Universidade Católi- } \\
\text { ca de Petrópolis - } \\
\text { UCP }\end{array}$ & $\begin{array}{l}\text { Gestão e sustentabi- } \\
\text { lidade do turismo }\end{array}$ & $\begin{array}{c}\text { Ecoturismo eTurismo } \\
\text { Rural }\end{array}$ & $\begin{array}{l}\text { Evany Rita Noel Carva- } \\
\text { Iho } \\
\text { Heitor de Brito Cintra }\end{array}$ & 2003 & $\begin{array}{c}\text { Desenvolver projetos e } \\
\text { estudos científicos volta- } \\
\text { dos para a utilização racio- } \\
\text { nal do meio ambiente, par- } \\
\text { tindo de um pressuposto } \\
\text { embasado na gestão do } \\
\text { turismo sustentável e na } \\
\text { visão sistêmica da ativida- } \\
\text { de. }\end{array}$ \\
\hline 4 & $\begin{array}{l}\text { Universidade Esta- } \\
\text { dual Paulista Júlio } \\
\text { de Mesquita Filho - } \\
\text { UNESP }\end{array}$ & $\begin{array}{c}\text { GRUTAS - Grupo de } \\
\text { Pesquisa em Turis- } \\
\text { mo de Aventura e } \\
\text { Sustentabilidade }\end{array}$ & Ecoturismo & $\begin{array}{l}\text { Sérgio Domingos de } \\
\text { Oliveira }\end{array}$ & 2006 & $\begin{array}{l}\text { Pesquisar perfil, alternati- } \\
\text { vas, potencialidades das } \\
\text { atividades em ecoturismo, } \\
\text { especialmente em Unida- } \\
\text { des de Conservação, áreas } \\
\text { de grande potencial de } \\
\text { desenvolvimento na região. }\end{array}$ \\
\hline 5 & $\begin{array}{l}\text { Universidade Fede- } \\
\text { ral da Bahia - UFBA }\end{array}$ & $\begin{array}{l}\text { NCTUR - Núcleo de } \\
\text { Estudos em Planeja- } \\
\text { mento e Gestão da } \\
\text { Cultura e do Turismo }\end{array}$ & $\begin{array}{l}\text { Estruturas de gover- } \\
\text { nança do ecoturismo } \\
\text { e turismo rural }\end{array}$ & Marcus Alban Suarez & 2004 & Não encontrado \\
\hline
\end{tabular}




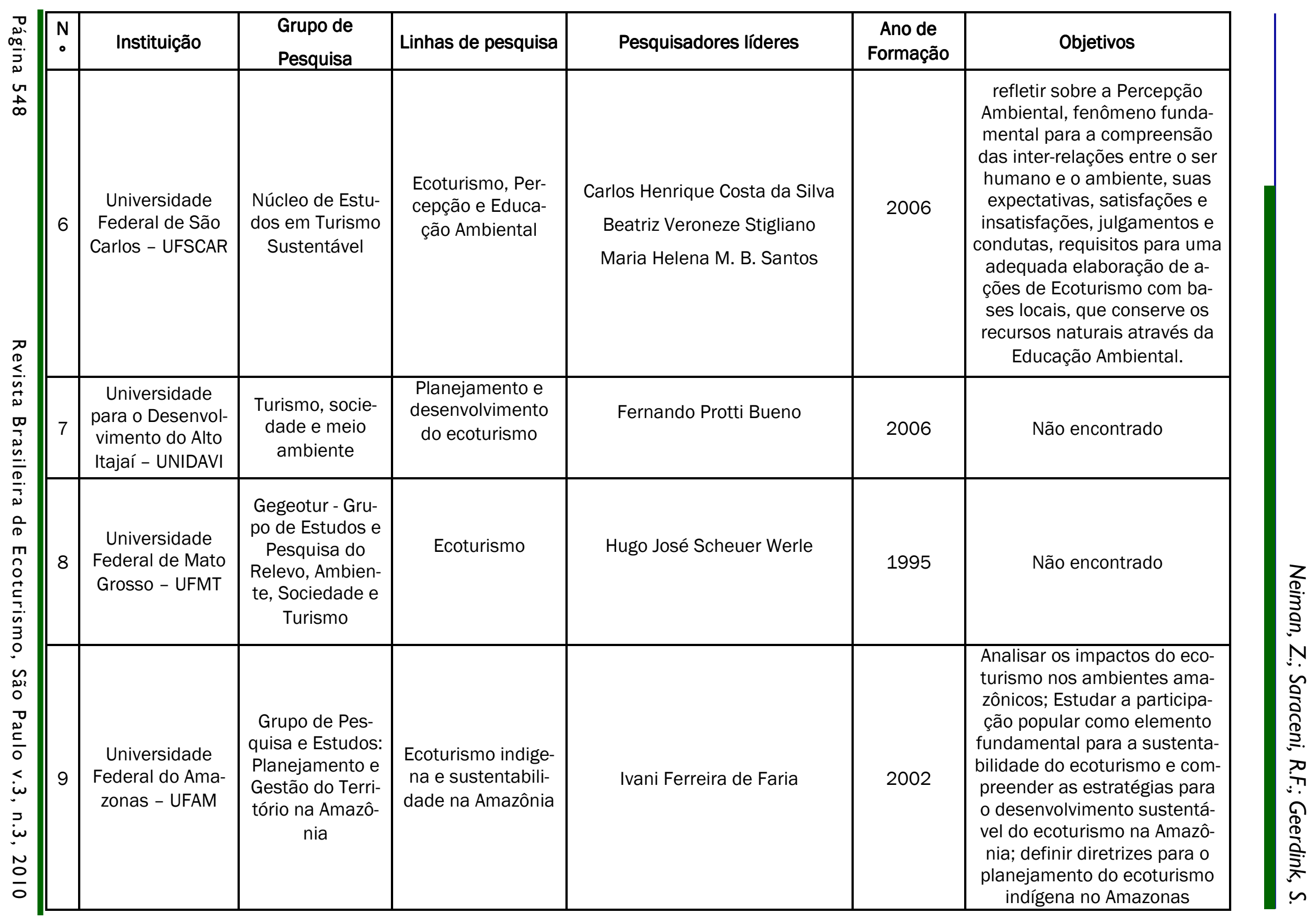




\begin{tabular}{|c|c|c|c|c|c|c|}
\hline $\mathrm{N}^{\circ}$ & Instituição & $\begin{array}{l}\text { Grupo de } \\
\text { Pesquisa }\end{array}$ & Linhas de pesquisa & Pesquisadores líderes & $\begin{array}{l}\text { Ano de } \\
\text { Formação }\end{array}$ & Objetivos \\
\hline 10 & $\begin{array}{l}\text { Instituto Nacio- } \\
\text { nal de Pesqui- } \\
\text { sas da Amazô- } \\
\text { nia - INPA }\end{array}$ & $\begin{array}{l}\text { Ecologia, Siste- } \\
\text { mática e Histó- } \\
\text { ria Natural da } \\
\text { Mastofauna } \\
\text { Amazônica }\end{array}$ & $\begin{array}{l}\text { Ecoturismo como } \\
\text { ferramenta na con- } \\
\text { servação de mamí- } \\
\text { feros aquáticos }\end{array}$ & $\begin{array}{c}\text { Vera Maria Ferreira da Silva } \\
\text { Maria Nazareth Ferreira da } \\
\text { Silva }\end{array}$ & 1994 & $\begin{array}{c}\text { Estudar o impacto de programas } \\
\text { de ecoturismo utilizando os mamí- } \\
\text { feros aquáticos da Amazônia, par- } \\
\text { ticularmente os botos da Amazô- } \\
\text { nia, promover o ordenamento e } \\
\text { gerar subsídios que regulem essa } \\
\text { atividade na região. }\end{array}$ \\
\hline 11 & $\begin{array}{l}\text { Universidade } \\
\text { Estadual do Pi- } \\
\text { auí - UESPI }\end{array}$ & $\begin{array}{c}\text { Grupo de Pesqui- } \\
\text { sas Botânicas em } \\
\text { Ecossistemas } \\
\text { Terrestres e A- } \\
\text { quáticos ECOTER- } \\
\text { RA } \\
\end{array}$ & $\begin{array}{l}\text { Ecoturismo e Edu- } \\
\text { cação Ambiental }\end{array}$ & $\begin{array}{l}\text { Francisco Soares Santos Filho } \\
\text { Maria Gardênia Sousa Batista }\end{array}$ & 2000 & $\begin{array}{c}\text { Propor estratégias que visem a } \\
\text { resolução dos impactos ligados à } \\
\text { atividade de Ecoturismo, bem co- } \\
\text { mo gerar estratégias de inserção } \\
\text { da Educação Ambiental neste ra- } \\
\text { mo. } \\
\end{array}$ \\
\hline 12 & $\begin{array}{l}\text { Universidade } \\
\text { Federal do Ama- } \\
\text { zonas - UFAM }\end{array}$ & $\begin{array}{l}\text { Gestão Ambien- } \\
\text { tal, Ecoturismo } \\
\text { e Âreas Protegi- } \\
\text { das }\end{array}$ & $\begin{array}{l}\text { Planejamento e } \\
\text { Gestão em Ecoturis- } \\
\text { mo }\end{array}$ & Julio Cesar Rodriguez Tello & 2000 & $\begin{array}{c}\text { Desenvolver a visão conservacio- } \\
\text { nista e de valorização do meio am- } \\
\text { biente a partir da educação e inter- } \\
\text { pretação ambiental; envolver as } \\
\text { comunidades na tomada de deci- } \\
\text { sões; harmonizar interesses eco- } \\
\text { nômicos, ambientais e sócio- } \\
\text { culturais nos projetos ecoturísticos } \\
\text { no plano da gestão participativa; } \\
\text { converter propriedades rurais e } \\
\text { áreas naturais de potencial em } \\
\text { produtos ecoturísticos; implemen- } \\
\text { tar a gestão ambiental na munici- } \\
\text { palização do turismo. }\end{array}$ \\
\hline 13 & $\begin{array}{l}\text { Universidade } \\
\text { Estadual de Pon- } \\
\text { ta Grossa - U- } \\
\text { EPG }\end{array}$ & $\begin{array}{l}\text { Gestão do Patri- } \\
\text { mônio Natural }\end{array}$ & $\begin{array}{l}\text { Educação ambien- } \\
\text { tal e ecoturismo }\end{array}$ & $\begin{array}{l}\text { Mario Sergio de Melo } \\
\text { Rosemeri Segecin Moro }\end{array}$ & 2000 & $\begin{array}{l}\text { Apoiar o desenvolvimento de ativi- } \\
\text { dades de educação ambiental jun- } \\
\text { to aos núcleos regionais de educa- } \\
\text { ção e escolas da rede de ensino e } \\
\text { propor atividades de ecoturismo } \\
\text { ambientalmente sustentáveis. }\end{array}$ \\
\hline
\end{tabular}




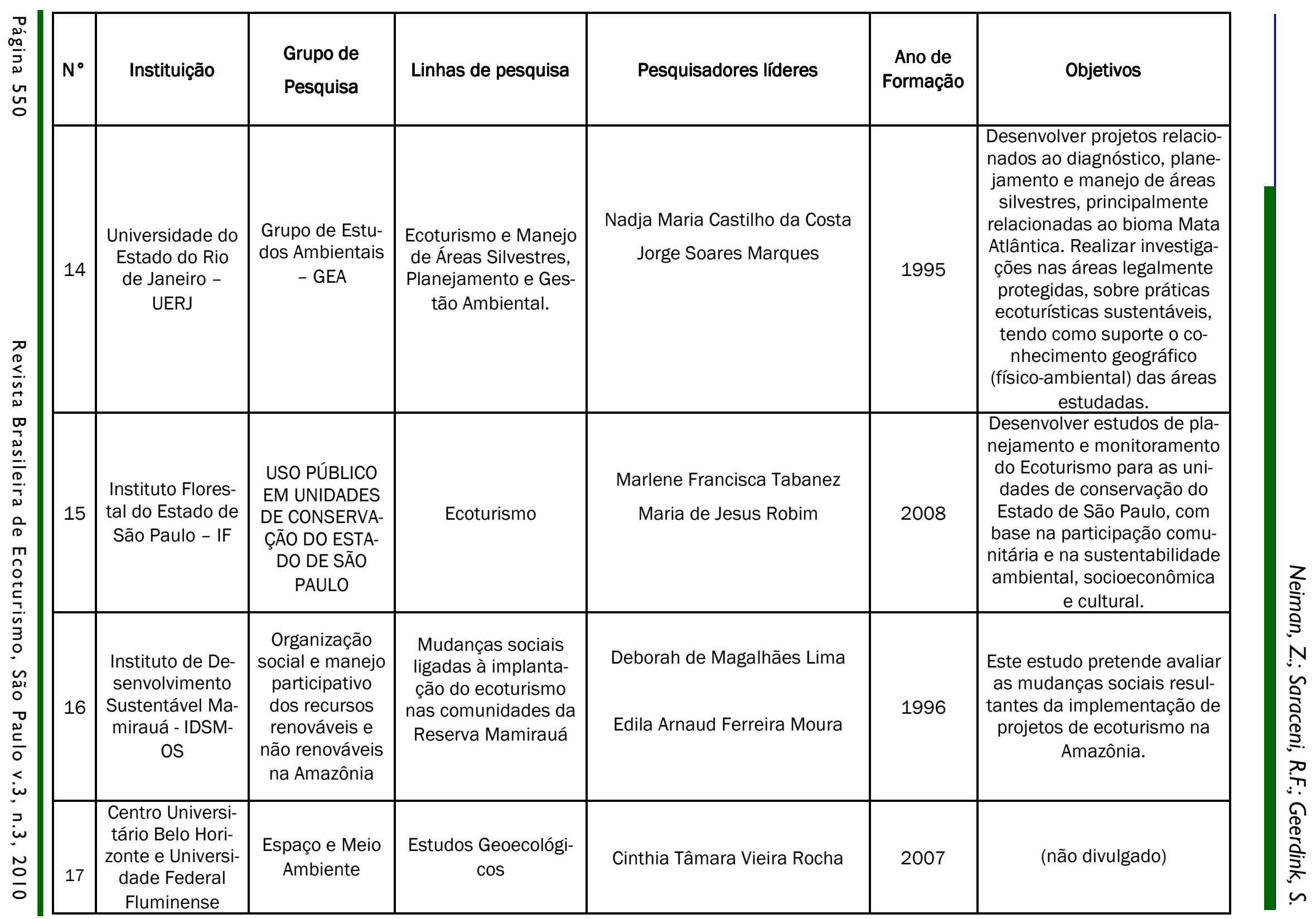




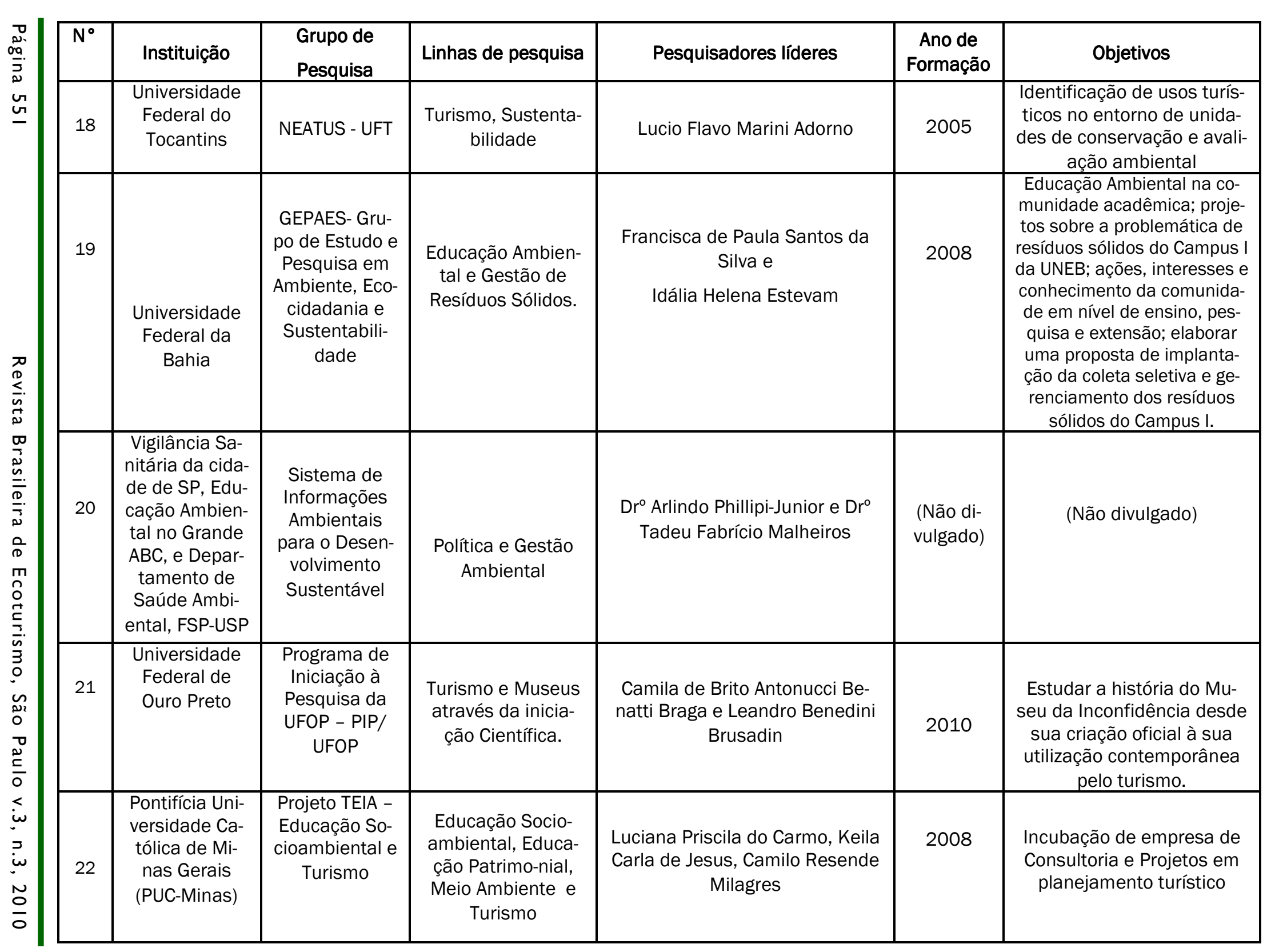




\begin{tabular}{|c|c|c|c|c|c|c|}
\hline $\mathrm{N}^{\circ}$ & Instituição & $\begin{array}{l}\text { Grupo de } \\
\text { Pesquisa }\end{array}$ & Linhas de pesquisa & Pesquisadores líderes & $\begin{array}{l}\text { Ano de } \\
\text { Formação }\end{array}$ & Objetivos \\
\hline $\begin{array}{c}\text { Un } \\
N\end{array}$ & $\begin{array}{c}\text { Universidade } \\
\text { Federal de } \\
\text { Santa Maria } \\
\text { - RS }\end{array}$ & $\begin{array}{l}\text { Grupo de Aná- } \\
\text { lise e interpre- } \\
\text { tação Ambien- } \\
\text { tal- GAIA }\end{array}$ & $\begin{array}{l}\text { Questões socioam- } \\
\text { bientais urbanas, } \\
\text { ecoturismo e Edu- } \\
\text { cação Ambiental }\end{array}$ & Adriano Severo Figueiró & 2005 & $\begin{array}{c}\text { Desenvolver e aplicar meto- } \\
\text { dologias que permitam di- } \\
\text { agnosticar e problematizar } \\
\text { os conflitos socioambien- } \\
\text { tais decorrentes dos pro- } \\
\text { cessos de transformação } \\
\text { da paisagem e das políticas } \\
\text { públicas em áreas urbanas } \\
\text { e rurais da metade sul do } \\
\text { RS }\end{array}$ \\
\hline 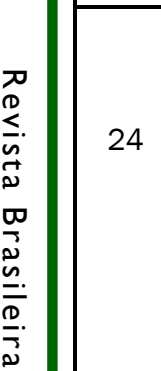 & $\begin{array}{l}\text { Universidade } \\
\text { Federal Flumi- } \\
\text { nense - UFF }\end{array}$ & $\begin{array}{l}\text { Turismo, Inclu- } \\
\text { são Social e } \\
\text { Sustentabili- } \\
\text { dade - TURis }\end{array}$ & $\begin{array}{l}\text { Educação e Patri- } \\
\text { mônio Ambiental; } \\
\text { Indicadores de Sus- } \\
\text { tentabilidade; Tu- } \\
\text { rismo e Inclusão } \\
\text { Social; Turismo e } \\
\text { suas dimensões } \\
\text { conceituais e epis- } \\
\text { temológicas }\end{array}$ & $\begin{array}{c}\text { Marcello Tomé e Carlos Alberto } \\
\text { Lidizia }\end{array}$ & 2007 & $\begin{array}{l}\text { Analisar o papel do Turismo } \\
\text { na Inclusão social e na con- } \\
\text { servação da natureza }\end{array}$ \\
\hline 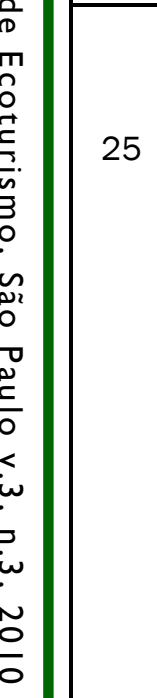 & $\begin{array}{c}\text { Departamento } \\
\text { de Saúde Am- } \\
\text { biental da Fa- } \\
\text { culdade de } \\
\text { Saúde Pública } \\
\text { da USP,rede } \\
\text { SIADES, FFL- } \\
\text { CH- Universi- } \\
\text { dade de São } \\
\text { Paulo, Ipá Ti- } \\
\text { uá Vivência } \\
\text { Ambiental, } \\
\text { Centro Univer- } \\
\text { sitário São } \\
\text { Camilo, } \\
\text { UNESP/Rio } \\
\text { Claro }\end{array}$ & $\begin{array}{l}\text { Rede SIADES } \\
\text { - Sistema de } \\
\text { Informações } \\
\text { Ambientais } \\
\text { para o Desen- } \\
\text { volvimento } \\
\text { Sustentável }\end{array}$ & $\begin{array}{l}\text { Política, planeja- } \\
\text { mento e gestão } \\
\text { ambiental }\end{array}$ & $\begin{array}{l}\text { Arlindo Philippi Jr e Tadeu Fabrí- } \\
\text { cio Malheiros }\end{array}$ & 2004 & $\begin{array}{l}\text { Contribuir para o estudo e } \\
\text { criação de sistemas de } \\
\text { informação em desenvolvi- } \\
\text { mento sustentável, que } \\
\text { possam fornecer às instân- } \\
\text { cias de decisão da socieda- } \\
\text { de informações, produtos e } \\
\text { serviços direcionados à } \\
\text { sustentabilidade do desen- } \\
\text { volvimento. }\end{array}$ \\
\hline
\end{tabular}




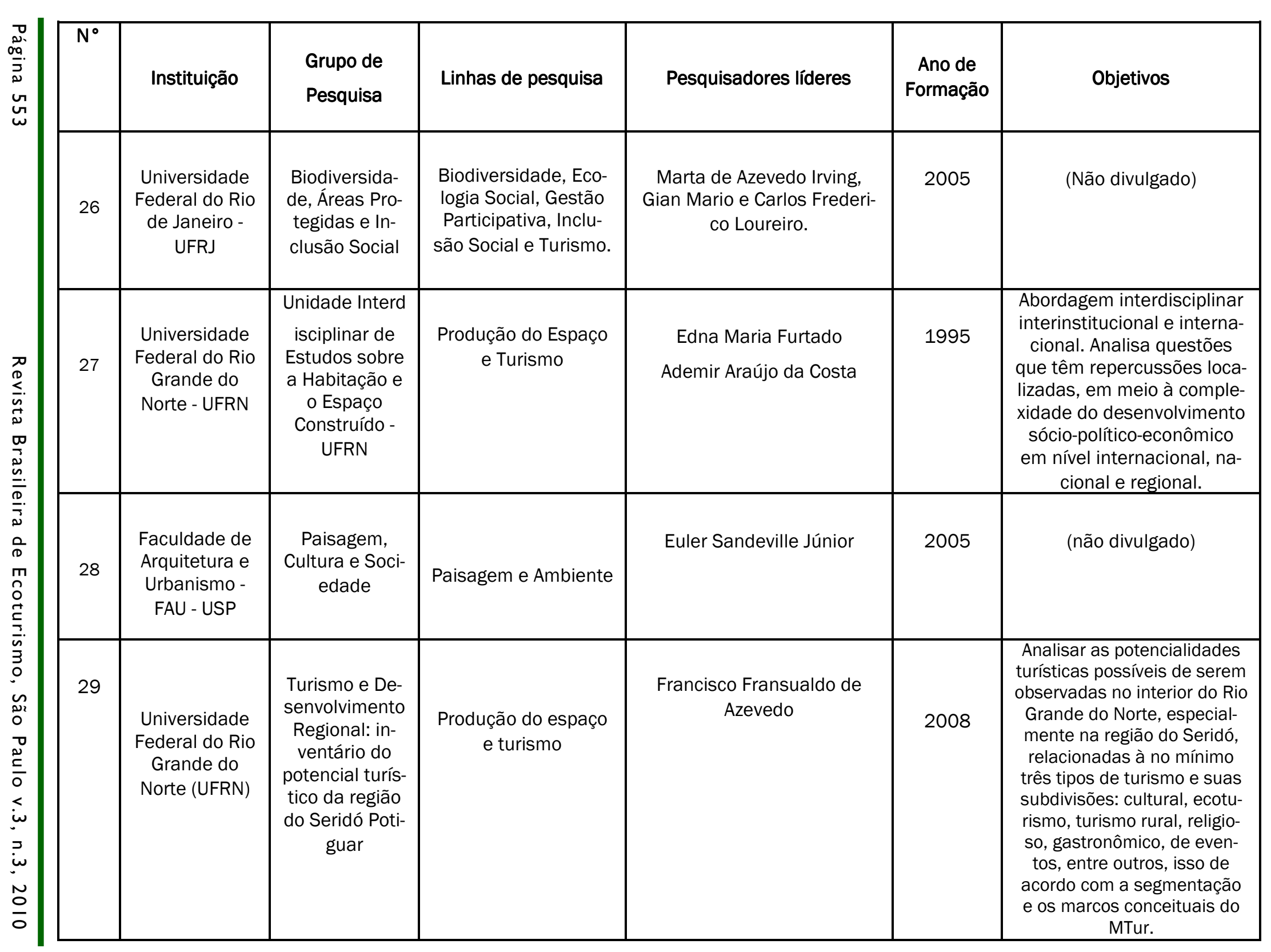




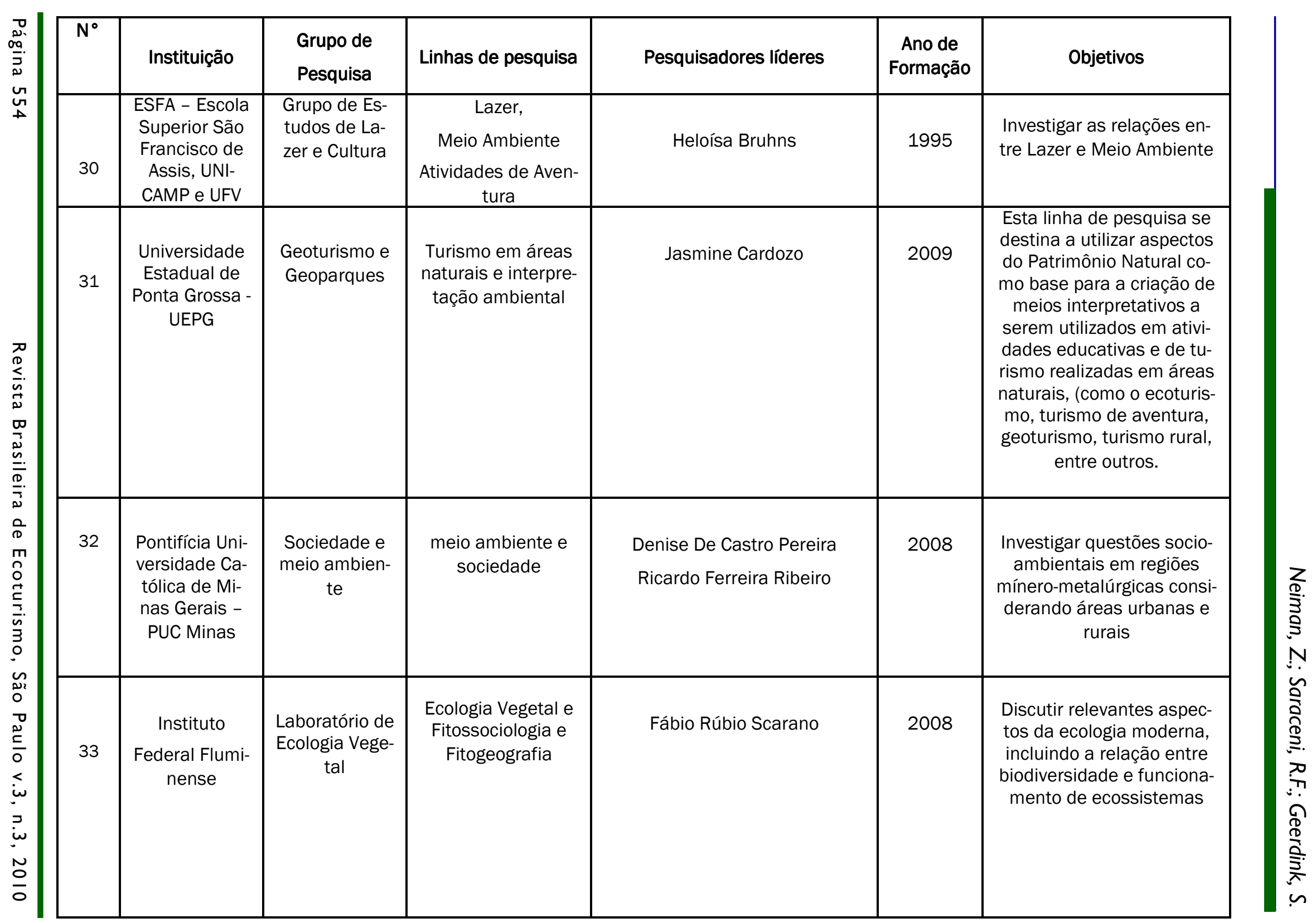




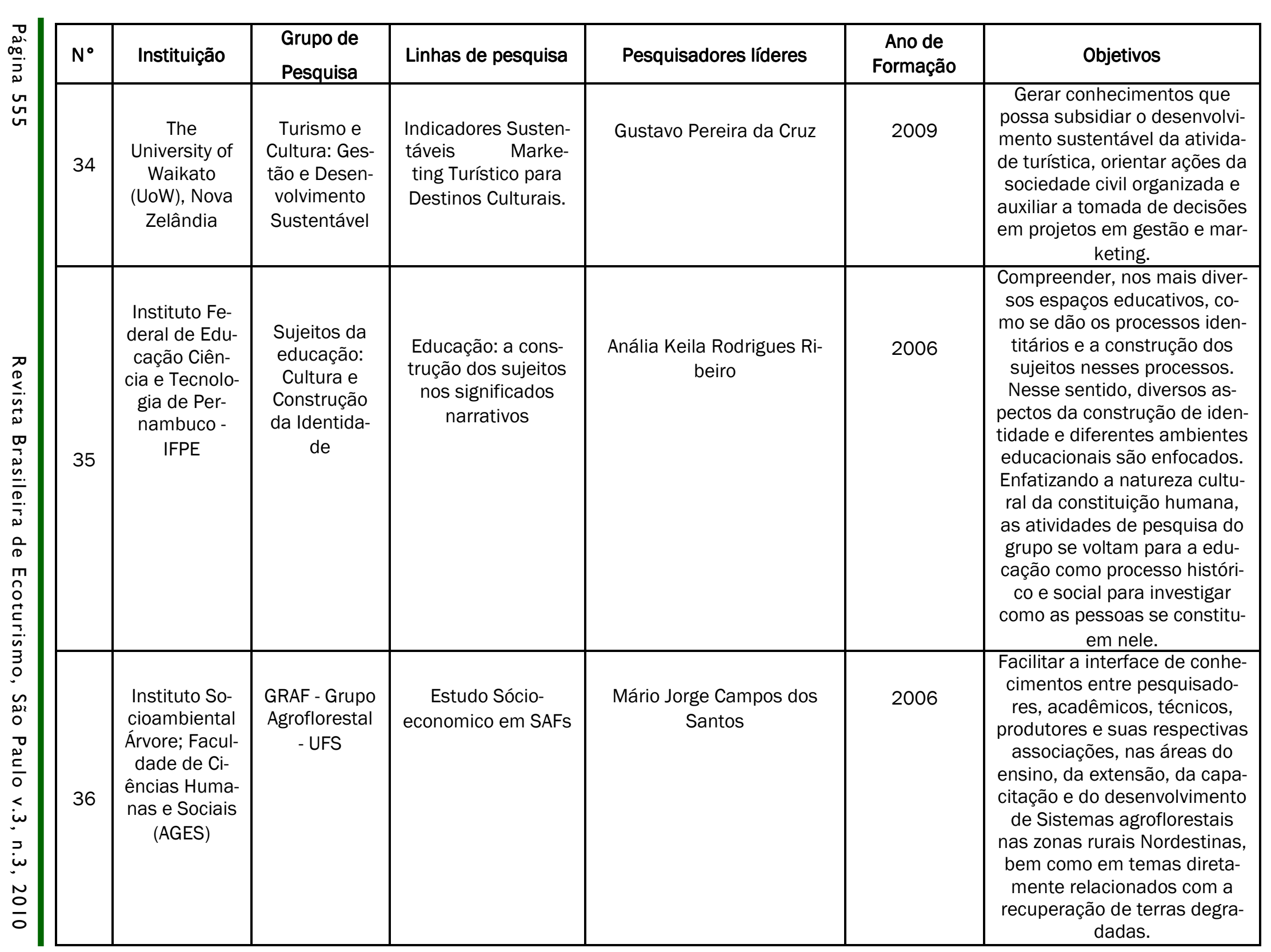

